\title{
Influence of Conditioning Temperature on the Quality, Nutritional Properties and Volatile Profile of Virgin Rapeseed Oil
}

\author{
Klara Kraljićl* , Tatjana \\ Stjepanović1, Marko \\ Obranović ${ }^{1}$, Milan \\ Pospišil|2, Sandra Balbino' \\ and Dubravka Škevin'
}

'University of Zagreb, Faculty of Food
Technology and Biotechnology,
Pierottijeva 6, Zagreb, Croatia
'University of Zagreb, Faculty of
Agriculture, Svetošimunska cesta 25,
Zagreb, Croatia

Received: 22 February 2018 Accepted: 19 November 2018

\footnotetext{
*Corresponding author: Phone: +38514605135; Fax: +38514605072 ;

E-mail:kkraljic@pbf.hr

ORCID IDs: 0000-0002-8544-5433 (Kraljić), 0000-0001-5861-744X (Stjepanović), 0000-0001-7868-1182 (Obranović), 0000-0002-9972-3940 (Pospišil), 0000-0003-3298-6209 (Balbino), 0000-0001-9215-6245 (Škevin)
}

\begin{abstract}
SUMMARY
Heating the rapeseed prior to the oil extraction is conducted to increase the oil yield but it can also induce changes of various components of the seed. These changes may affect the composition of the volatile and non-volatile compounds of produced virgin rapeseed oil. The aim of our study is to determine the impact of different conditioning temperatures $\left(60,80\right.$ and $\left.100^{\circ} \mathrm{C}\right)$ on the quality, nutritional value, aroma profile and sensory characteristics of virgin rapeseed oil. Conditioning the seeds at all three temperatures had no influence on the quality and major nutritional components (fatty acids and tocopherols) of the produced oil. However, temperature increase caused an exponential increase of canolol and significant changes in the aroma and sensory profile of the produced oil samples. The dominant volatile compounds of cold-pressed and virgin oil produced at 60 ${ }^{\circ} \mathrm{C}$ were enzymatic degradation products of glucosinolates (isothiocyanates and epithionitriles), responsible for pronounced seed-like flavour of these types of oil. Increasing production temperature deactivated enzymes and caused thermal decomposition of seed components and increment of nitriles, aldehydes, pyrazines and furanes, carriers of nutty and roasty flavour. These results can help producers to design virgin rapeseed oil with specific and desirable sensory characteristics.
\end{abstract}

Key words: rapeseed oil, seed conditioning, nutritional value, volatile components, sensory analysis

\section{INTRODUCTION}

Rapeseed oil is one of the most widely used types of oil in the world and it currently ranks third in the production quantity (1). Growing awareness about its nutritional value brought increase in food usage for almost $50 \%$ in the past decade (2). Specific fatty acid composition, high percentage of unsaturated fatty acids and an ideal 2:1 ratio of $\omega-6$ to $\omega-3$ fatty acids have the highest impact on the nutritional value of rapeseed oil. Furthermore, significant amounts of sterols and tocopherols and a fair amount of polyphenols contribute considerably to its oxidative stability and nutritional value $(3,4)$.

Majority of rapeseed oil today is placed on the market as refined rapeseed oil. This type of oil is characterized by a neutral odour and flavour, familiar and acceptable to the consumers. However, term 'refined' causes negative connotations among the consumers because of the belief that all of the aforementioned beneficial and nutritional components are removed or degraded during refining process. That is why nowadays another group of products, nonrefined types of oil, is of growing interest among the consumers. Nonrefined oil is produced only by mechanical procedures and can be placed on the market as cold-pressed or as virgin oil. The difference between these two types of oil is in the application of heat. When producing virgin oil, seeds are heated during conditioning phase, prior to pressing (5). Conditioning of the seed is conducted to improve oil yield, but it can also significantly increase the amount of bioactive compounds of virgin rapeseed oil. Heat-induced disruption of the cell improves extractability of tocopherols and sterols in the oil $(4,6,7)$. However, conditioning of the rapeseed has the greatest impact on the increase of the phenolic compounds, especially canolol, a specific phenolic compound of rapeseed oil, formed by heat-induced decarboxylation of 
sinapic acid (8). Shrestha and De Meulenaer (9) reported more than 150 times higher concentration of canolol in oil produced from conditioned seeds than in cold-pressed rapeseed oil.

Apart from the economical and nutritional aspects of the oil, conditioning of the seeds is known to have a great influence on the sensory characteristic of some types of virgin oil such as pumpkin, peanut or sesame oil (10-12). Good quality cold-pressed rapeseed oil has an expressed seed-like flavour characterized by a sensation resembling asparagus, cabbage, fresh green vegetable, sometimes with the sulfuric note (13). Aforementioned attributes are caused by specific volatile compounds formed during enzymatic degradation of glucosinolates (14). Applying the heat during production process causes inactivation of the enzymes and induces thermal degradation. These changes most likely affect sensory attributes of virgin rapeseed oil. That is why the aim of our study is to determine changes in nutritional value, volatile compounds and sensory characteristics caused by application of different conditioning temperatures during the production of virgin rapeseed oil.

\section{MATERIALS AND METHODS}

\section{Reagents}

Reagents used in this study were obtained from commercial sources: petroleum ether, diethyl ether, ethanol, isooctane, acetic acid, methanol, $n$-hexane, 2-propanol, acetonitrile, phosphoric acid, alkane standard solution $\left(C_{8}-C_{20}\right)$, sinapic acid (Sigma-Aldrich Chemie, Taufkirchen, Germany), and FAME mix (C4-C24) (Supelco, Sigma-Aldrich, Merck, Bellefonte, PA, USA). Tocopherol homologues ( $\alpha-, \beta-, \gamma$ - and $\delta$-tocopherol) were purchased from Merck, Darmstadt, Germany. Plastochromanol-8 was given to us by Dr Jerzy Kruk from Jagiellonian University, Kraków, Poland.

\section{Rapeseed oil production}

Oil samples used in present research were either produced by cold pressing of unheated seeds (cold-pressed rapeseed oil) or by pressing seeds conditioned by heating at different temperatures to obtain virgin rapeseed oil. Rapeseed cultivar PR46W20 (Pioneer, Johnston, IA, USA) grown at the experimental field of the Faculty of Agriculture, University of Zagreb, Zagreb, Croatia, was used. Prior to each production procedure, 1 $\mathrm{kg}$ of seeds was ground using standard electric coffee grinder (Gorenje, Velenje, Slovenia). Cold-pressed oil was extracted using laboratory expeller press (Monforts \& Reiners, Rheydt, Germany) with temperature not exceeding $40{ }^{\circ} \mathrm{C}$. For virgin rapeseed oil production, ground rapeseeds were first heated for 30 min with constant stirring at 60,80 or $100{ }^{\circ} \mathrm{C}$. Conditioning of the seeds was carried out in the specially constructed heater with stirrer placed in the double-walled stainless steel container. Seeds were heated indirectly by thermal conduction, and the heating was achieved by placing the glycerol between double walls and heating it with electric heater. Heater was also equipped with temperature control that can maintain temperature at a set temperature $\pm 2{ }^{\circ} \mathrm{C}$. During this phase of oil production, portions of water were added totalling 80, 140 and 240 $\mathrm{mL}$, respectively. Conditioned seeds were then pressed on the same laboratory expeller press used for cold pressed oil production. All produced oil samples were filtered through filter paper (Whatman grade 1, pore size $11 \mu \mathrm{m}$; Sigma-Aldrich Chemie, Merck) and stored in the dark glass bottles under nitrogen at room temperature. All analyses of the oil were performed within two weeks of the production.

\section{Oil yield}

Oil and moisture content of the seeds and cakes after oil pressing were determined using standard ISO methods $(15,16)$. Moisture content was determined by drying $5 \mathrm{~g}$ of unground seeds, or ground cake, in metal vessel at $103^{\circ} \mathrm{C}$ for 1 hour until constant mass was achieved. For the determination of oil content, standard method of extraction of non-polar component using petroleum ether was used. In brief, $10 \mathrm{~g}$ of seeds were ground in an electric mill (Gorenje), placed in extraction cellulose thimble, closed with cotton wool and placed into the Soxhlet syphoning-type extractor. The extractor was placed onto the $250-\mathrm{mL}$ round flask and $150 \mathrm{~mL}$ of petroleum ether were added. Upper end of the extractor was attached to a water condenser. Assembled apparatus was placed on the electric heating bath (INKO d.d., Zagreb, Croatia) and extraction was carried out with reflux for $8 \mathrm{~h}$. After that, greater part of the solvent was removed from the flask by distillation, and the rest of the solvent was removed by heating the flask in the oven at $103^{\circ} \mathrm{C}$ for $60 \mathrm{~min}$. Drying of the flask was repeated for 30 min until constant mass of oil was achieved. All analyses were performed in triplicates. The obtained data were used to calculate oil yield in each extraction process. Oil yield is defined as the percentage of oil extracted by each process on a total oil extractable basis.

\section{Determination of oil quality parameters}

Quality parameters of produced oil, free fatty acids (FFA) and peroxide value (PV), were determined using standard ISO methods $(17,18)$. For FFA determination, $10 \mathrm{~g}$ of oil was weighed into the $250-\mathrm{mL}$ Erlenmeyer flask. A volume of 50 $\mathrm{mL}$ of neutral mixture of ethanol ( $96 \%$ ) and diethyl ether (peroxide-free) in equal volumes was added to dissolve the test portion. Phenolphthalein was added as an indicator and the mixture was titrated with standard sodium hydroxide solution $(0.1 \mathrm{~mol} / \mathrm{L})$ (17). PV was determined according to ISO 3960:2007 method (18). A mass of $5 \mathrm{~g}$ of the oil was dissolved in $50 \mathrm{~mL}$ of the glacial acetic acid/isooctane solution $(3 / 2, \mathrm{~V} / \mathrm{V})$, then $0.5 \mathrm{~mL}$ of saturated potassium iodide solution was added, and closed Erlenmeyer flask was mixed for exactly $60 \mathrm{~s}$. Water $(30 \mathrm{~mL})$ was added immediately to the flask, and liberated iodine was titrated with $0.01 \mathrm{~mol} / \mathrm{L}$ sodium thiosulfate solution. A volume of $0.5 \mathrm{~mL}$ of starch solution $(0.1 \mathrm{~g} / \mathrm{L})$ was added as an indicator. Each procedure was repeated three times for each oil sample. 


\section{Determination of fatty acid composition}

Gas chromatography was used to determine fatty acid composition of produced rapeseed oil samples. Fatty acid methyl esters were prepared by transesterification with methanol according to ISO 5509:2000 method (19). A mass of $60 \mathrm{mg}$ of oil was dissolved in $4 \mathrm{~mL}$ of isooctane and 200 $\mu \mathrm{L}$ of potasium hydroxide $(2 \mathrm{~mol} / \mathrm{L}$ ) were added. Mixture was vigorously shaken using vortex (IKA-Werke GmbH \& Co., Staufen, Germany) for $30 \mathrm{~s}$ and left for a few munutes at room temperature to react. Then, $1 \mathrm{~g}$ of sodium hydrogen sulphate monohydrate was added, mixed and clear supernatant containing methyl esters was transferred into the vial. The prepared methyl esters were injected $(1 \mu \mathrm{L})$ into an Agilent Technologies 6890N Network GC system (Santa Clara, CA, USA) equipped with flame ionisation detector. Fatty acid methyl esters were separated on a DB-23 capillary column ( $60 \mathrm{~m} \times 0.25 \mathrm{~mm} \times 0.25 \mu \mathrm{m}$; Agilent Technologies). Helium was used as carrier gas with a constant flow of $1.5 \mathrm{~mL} / \mathrm{min}$. Injector temperature was set at $250^{\circ} \mathrm{C}$ and detector at $280^{\circ} \mathrm{C}$. Owen temperature was programmed to increase by $7^{\circ} \mathrm{C} /$ min from initial $60^{\circ} \mathrm{C}$ to final temperature of $220^{\circ} \mathrm{C}$ where it was held for $17 \mathrm{~min}$. The split ratio was 30:1. Fatty acid methyl esters were identified by comparison of their retention times with those of the commercial standards. The content of each fatty acid is expressed as a percentage of total fatty acids, and the results are presented as the mean value of three parallel determinations.

\section{Determination of tocopherols}

Tocopherol content was determined following ISO 9936:2006 method (20). A volume of $50 \mu \mathrm{L}$ of $1 \%(\mathrm{~m} / \mathrm{V})$ oil solution in $n$-hexane was injected into a Varian HPLC system (Palo Alto, CA, USA) equipped with a fluorescence detector and LiChroCART Silica 60 column $(250 \mathrm{~mm} \times 4.6 \mathrm{~mm}, 5 \mu \mathrm{m}$; Merck). Separation of tocopherols was performed at room temperature by isocratic chromatography using $0.7 \%$ 2-propanol in $n$-hexane as a mobile phase. The flow rate of mobile phase was $0.9 \mathrm{~mL} / \mathrm{min}$. Tocopherols were detected at 295 $\mathrm{nm}$ excitation wavelength and $330 \mathrm{~nm}$ emission wavelength. Quantification of individual tocopherols was performed using calibration curves of $\alpha^{-}, \beta-, \gamma^{-}$, and $\delta$-tocopherols and plastochromanol-8. The analysis was performed in triplicate.

\section{Determination of canolol content}

Canolol content was determined using high-performance liquid chromatography (HPLC; Varian, Palo Alto, CA, USA) equipped with a UV detector, following the method we described in our earlier research (7). Canolol was identified by comparing its retention time and spectra with the ones of a compound identified as canolol in the above-mentioned research, and quantified by using calibration curve for sinapic acid. Results are given as mean value of three parallel determinations.

\section{Determination of volatile components}

Volatile components were isolated using headspace solid-phase microextraction (SPME) and their content and composition were determined using gas chromatography/mass spectrometry (GC/MS). Divinylbensene/carboxen/polydimethylsiloxane (DVB/CAR/PDMS) fibre ( $2 \mathrm{~cm}$ long) with 50/30 $\mu \mathrm{m}$ film thickness (Supelco, Sigma-Aldrich, Merck) was used. Rapeseed oil ( $10 \mathrm{~g}$ ) was weighed into a $20-\mathrm{mL}$ vial fitted with a silicone septum which was then placed in a heating block at 40 ${ }^{\circ} \mathrm{C}$ with constant magnetic stirring (Pierce Reacti-Therm Heating/Stirring Module, Artisan, Champaign, IL, USA). After $10 \mathrm{~min}$ of sample conditioning, SPME fibre was exposed for $30 \mathrm{~min}$, and immediately desorbed in the gas chromatograph injector in a splitless mode at $260^{\circ} \mathrm{C}$ for $1 \mathrm{~min}$. Samples were analysed using an Agilent Technologies 6890N Network GC system coupled with an Agilent Technologies 5973 inert mass selective detector. Volatile compounds were resolved on a ZB- 5 column

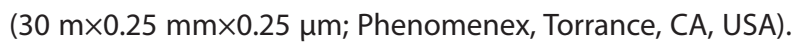
Owen temperature was held at initial temperature of $35^{\circ} \mathrm{C}$ for $10 \mathrm{~min}$, after which it was increased to $200^{\circ} \mathrm{C}$ at $5{ }^{\circ} \mathrm{C} / \mathrm{min}$ rate, followed by an increase to $250^{\circ} \mathrm{C}$ at $20^{\circ} \mathrm{C} / \mathrm{min}$. This final temperature was held for additional $5 \mathrm{~min}$. The temperature of the ion source and the transfer line were 230 and $280{ }^{\circ} \mathrm{C}$, respectively. Helium was used as carrier gas with a constant flow of 1.0 $\mathrm{mL} / \mathrm{min}$. Mass spectra were recorded in the $50-550$ mass range. The $n$-alkanes $\left(C_{8}-C_{20}\right)$ were run under the same conditions as the samples to calculate the Kovats index values. Identification of the compounds was based on the comparison of the mass spectra with the records in NIST mass spectral library (21) and by comparing Kovats index with the ones from the same library (21) or from the literature $(10,14,22)$. The minimal $s / n$ ratio for the integration of the peaks was 13. Each of the four samples of oil was analysed at least three times. Results of the volatile compound determination are expressed as peak area of individual component.

\section{Sensory analysis}

Sensory analyses were carried out by a panel of six panellists chosen and trained at our laboratory using a method described by Brühl and Matthäus (13). The panel consisted of two male and four female panellists, all non-smokers and aged between 30 and 50. Panellists were asked to evaluate colour, clarity and flavour which is described by attributes seed-like, nutty, roasty, burnt and rancid using a scale from 0 to 5 (zero representing the absence of an attribute and five representing highly expressed sensory characteristic). Oil samples (15 mL) were served to the panellists at room temperature, and water and unsalted bread were given to rinse their mouths between samples. Each sample was evaluated twice, at two different sessions.

\section{Data analysis}

All data, except for the sensory analysis, are expressed as the mean value of minimum three determinations \pm standard 
deviation. Results of sensory analysis are presented as mean value of two parallel determinations. To determine the effect of conditioning temperature on the oil yield, oil quality and composition of volatile and non-volatile components, single factor analysis of variance (ANOVA) was performed followed by Tukey's honestly significant difference (HSD) test. A significance level of $p \leq 0.05$ was applied. Statistical analysis was performed using STATISTICA v. 10 (23).

\section{RESULTS AND DISCUSSION}

Conditioning of the seeds is a process designed to increase oil yield, thus having a beneficial economic effect on the oil production (3). Furthermore, this process can also improve nutritional value and alter sensory characteristic of the produced vegetable oil $(10,14,24)$. Sensory characteristics probably have the greatest impact on the consumer choice whether to use a certain oil or not, and these characteristics are under the direct influence of volatile and non-volatile components formed in the seed during oil production, storage or usage. It is crucial to understand the changes that volatile and non-volatile components undergo during production in order to obtain high-quality virgin rapeseed oil with desirable sensory characteristics. The aim of our study was to determine the dynamics of these changes as a result of temperature alterations during conditioning process in the virgin rapeseed oil production.

Fig. 1 shows oil yield of cold-pressed and virgin rapeseed oil production. We extracted $72 \%$ of available oil by cold pressing. Conditioning the seeds prior to oil pressing increased oil yield for 1.5-14.4\%. Data analysis showed that oil yield increase significantly depends on the temperature used during the conditioning process. This is because the addition of water and heat during the conditioning cause denaturation of seed proteins. As a result, small droplets of oil coalesce into larger ones that are easier to extract (3). Conditioning of the seeds at $60^{\circ} \mathrm{C}$ gave only $2.5 \%$ higher oil yield than cold pressing, probably because the used temperature was not high enough to cause a required degree of protein coagulation. On the other hand, conditioning the seeds at $100^{\circ} \mathrm{C}$ gave even smaller increase in oil yield than cold pressing (1.5\%), probably because the seed was too dry after conditioning at $100^{\circ} \mathrm{C}$. To obtain adequate oil yield, moisture of the seed prior to the extraction should be 5-7\% (3). Although we added substantial amount of water during the conditioning at $100{ }^{\circ} \mathrm{C}(240$ $\mathrm{mL} / \mathrm{kg}$ ), high temperature of the process caused evaporation of the water immediately after its addition. To obtain better oil yield at such high temperatures, one should consider altering the production process. The best oil yield was obtained after conditioning the seed at $80^{\circ} \mathrm{C}$ for $30 \mathrm{~min}(86.6 \%)$, which can be considered as an optimal temperature for virgin rapeseed oil production from an economical point of view.

Quality parameters of produced oil are shown in Table 1. All samples of oil produced in this research were of high quality. Free fatty acids (FFA), which indicate hydrolytic deterioration of oil, were far below Codex limits (5) of $2 \%$ oleic fatty

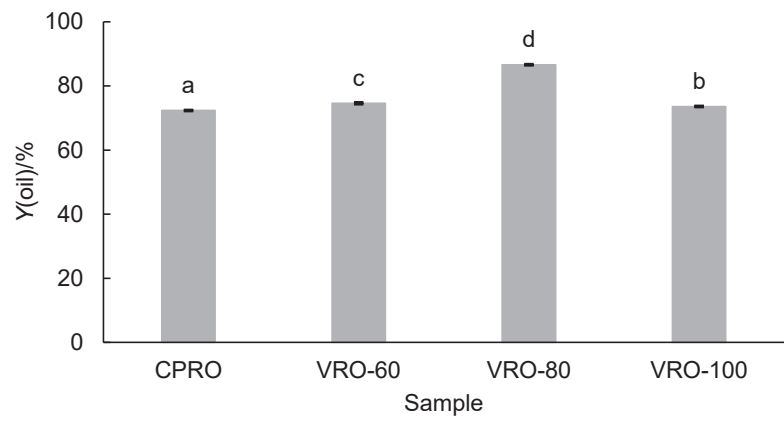

Fig. 1. Oil yield $(Y)$ of cold-pressed rapeseed oil (CPRO) and virgin rapeseed oil (VRO) production. Numbers 60,80 and 100 indicate temperature of the seed conditioning before pressing. Samples labelled with different lowercase letters are significantly different (Tukey's test, $p \leq 0.05$ )

acid, an equivalent to an acid value of $\mathrm{KOH}$ of $4 \mathrm{mg} / \mathrm{g}$ of oil. Peroxide value (PV), an indicator of oxidation of fats and oils, of all produced oil samples was also below the limits given by the Codex (5). Applying the heat during conditioning had no significant influence on either of the determined quality parameters ( $p>0.05)$.

Table 1. Free fatty acids (FFA; expressed as percentage of oleic acid) and peroxide value (PV) of cold-pressed rapeseed oil (CPRO) and virgin rapeseed oil (VRO) produced after conditioning of the seeds at 60,80 and $100^{\circ} \mathrm{C}$

\begin{tabular}{lcccc} 
& \multicolumn{4}{c}{ Sample } \\
\cline { 2 - 5 } Parameter & CPRO & VRO-60 & VRO-80 & VRO-100 \\
$W(\mathrm{FFA}) / \%$ & $0.16 \pm 0.01$ & $0.22 \pm 0.02$ & $0.19 \pm 0.01$ & $0.21 \pm 0.03$ \\
$\mathrm{PV} /(\mathrm{mmol} / \mathrm{kg})$ & $1.3 \pm 0.2$ & $0.9 \pm 0.1$ & $0.9 \pm 0.1$ & $1.1 \pm 0.3$
\end{tabular}

Dominant fatty acid in all produced oil samples was oleic fatty acid, followed by linoleic and linolenic acids, while saturated fatty acids accounted for about $7 \%$ (Table 2). These results are in accordance with previous reports $(3,25)$ and are within the limits given by Codex (5). Furthermore, conditioning had no significant influence on fatty acid composition of produced oil ( $p>0.05$ ), not even on polyunsaturated fatty acids which are susceptible to oxidation and make around $30 \%$ of total fatty acids in produced rapeseed oil. Stability of fatty acids during the conditioning justifies the application of this process in the production of rapeseed oil because fatty acid composition has the greatest influence on its high nutritional value. According to the recommendations of US Food and Drug Administration (26), eating about 1.5 tablespoons of rapeseed oil daily may reduce the risk of coronary heart disease due to its unsaturated fatty acids, more specifically to an ideal 2:1 $\omega-6: \omega-3$ ratio of rapeseed oil. Other components that significantly contribute to the nutritional value of rapeseed oil are antioxidants (3). Rapeseed oil is rich in $\gamma$-tocopherol, followed by a-tocopherol and low amounts of $\delta$-tocopherol (27). In addition, rapeseed oil contains plastochromanol-8, a chromanol derivative related to the tocopherols with antioxidant properties (28). Analysis of tocopherol content and composition of the obtained rapeseed oil are given in Table 2. a-Tocopherol (262$280 \mathrm{mg} / \mathrm{kg}$ ), $\gamma$-tocopherol (404-418 mg/kg) and $\delta$-tocopherol 
(1 mg/kg) were found in all produced oil samples, while homologue of $\beta$-tocopherol was not detected. These results are in accordance with Codex limits (5) and are similar to the ones previously reported by Szydłowska-Czerniak et al. (29). Tocopherol homologues were not affected by heat during conditioning ( $p>0.05$ ). However, conditioning had significant effect on plastochromanol-8 content, which increased with the used temperature $(p \leq 0.05)$. Furthermore, increase of the temperature during conditioning significantly increased canolol content of the produced virgin oil (Fig. 2). Canolol is a specific phenolic compound of rapeseed oil, formed by heat-induced decarboxylation of sinapic acid, a phenolic acid abundantly found in the rapeseed (8). Taking this into consideration, very low concentrations of canolol were found in the cold-pressed oil $\left(4 \mathrm{mg} / \mathrm{kg}\right.$ ). Conditioning seeds at $60^{\circ} \mathrm{C}$ doubled the concentration of canolol in the oil, but these two oil samples were not significantly different from each other and can be characterized as the oil with very low canolol content. Further increase of the temperature caused exponential increase of the canolol content in the produced oil. Virgin oil preconditioned at $80^{\circ} \mathrm{C}$ had 16 times more canolol than the cold-pressed oil, while canolol content of the oil preconditioned at $100{ }^{\circ} \mathrm{C}$ was 74 times higher than in the cold-pressed one. The increase of canolol concentration with the used temperature is consistent with previous studies $(8,29)$. Taking into consideration quality parameters and non-volatile components, fatty acids, tocopherols and polyphenols, which directly affect nutritional value of rapeseed oil, higher temperatures of conditioning prior to the oil extraction have more favourable effect. Increasing the temperature up to $100{ }^{\circ} \mathrm{C}$ led to the production of the virgin rapeseed oil rich in canolol and without any negative effects on fatty acids and tocopherols.

Table 2. Fatty acid and tocopherol composition of cold-pressed rapeseed oil (CPRO) and virgin rapeseed oil (VRO) produced after conditioning of the seeds at 60,80 and $100^{\circ} \mathrm{C}$

\begin{tabular}{ccccc} 
& \multicolumn{4}{c}{ Sample } \\
\cline { 2 - 5 } Component & CPRO & VRO-60 & VRO-80 & VRO-100 \\
\cline { 2 - 5 } C16:0 & $4.8 \pm 0.0$ & $4.8 \pm 0.0$ & $4.9 \pm 0.0$ & $4.8 \pm 0.0$ \\
C16:1 & $0.2 \pm 0.0$ & $0.2 \pm 0.0$ & $0.3 \pm 0.0$ & $0.2 \pm 0.0$ \\
C17:1 & $0.1 \pm 0.0$ & $0.1 \pm 0.0$ & $0.1 \pm 0.0$ & $0.1 \pm 0.0$ \\
C18:0 & $1.5 \pm 0.0$ & $1.5 \pm 0.0$ & $1.5 \pm 0.0$ & $1.5 \pm 0.0$ \\
C18:1 & $60.9 \pm 0.0$ & $61.2 \pm 0.0$ & $60.5 \pm 0.0$ & $60.9 \pm 0.0$ \\
C18:2 & $20.9 \pm 0.0$ & $20.7 \pm 0.0$ & $21.2 \pm 0.0$ & $21.0 \pm 0.0$ \\
C18:3 & $9.6 \pm 0.0$ & $9.6 \pm 0.0$ & $9.7 \pm 0.0$ & $9.6 \pm 0.0$ \\
C20:0 & $0.5 \pm 0.0$ & $0.5 \pm 0.0$ & $0.5 \pm 0.0$ & $0.5 \pm 0.0$ \\
C20:1 & $1.0 \pm 0.0$ & $1.0 \pm 0.0$ & $1.0 \pm 0.0$ & $1.0 \pm 0.0$ \\
C22:0 & $0.3 \pm 0.0$ & $0.3 \pm 0.0$ & $0.3 \pm 0.0$ & $0.3 \pm 0.0$ \\
& & $w($ tocopherol $) /(\mathrm{mg} / \mathrm{kg})$ \\
a-tocopherol & $262 \pm 3$ & $280 \pm 8$ & $280 \pm 11$ & $270 \pm 2$ \\
Y- tocopherol & $405 \pm 1$ & $418 \pm 12$ & $404 \pm 17$ & $417 \pm 20$ \\
8- tocopherol & $1 \pm 0$ & $1 \pm 1$ & $1 \pm 0$ & tr \\
plastochromanol-8 & $(77 \pm 1)^{\mathrm{a}}$ & $(94 \pm 3)^{\mathrm{b}}$ & $(107 \pm 5)^{\mathrm{bc}}$ & $(113 \pm 1)^{\mathrm{c}}$
\end{tabular}

Different lowercase letters in the row indicate significant difference between samples (Tukey's test, $\mathrm{p} \leq 0.05)$. $\mathrm{tr}=\operatorname{traces}(<0.5 \mathrm{mg} / \mathrm{kg})$

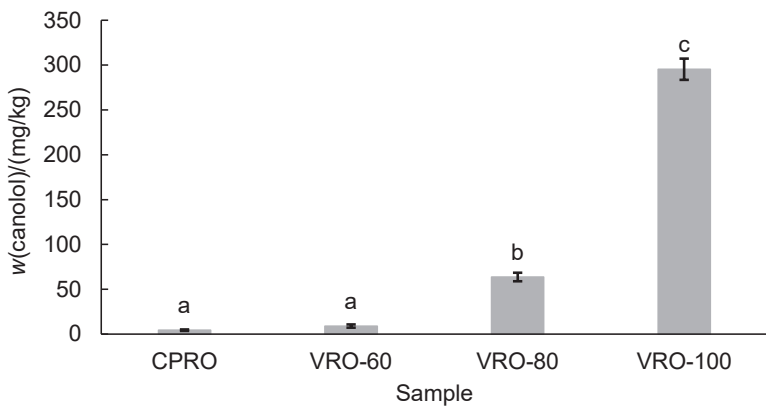

Fig. 2. Canolol content $(w)$ of rapeseed oil samples produced by cold pressing (CPRO) or by pressing after conditioning (VRO) at different temperatures $\left(60,80\right.$ or $\left.100^{\circ} \mathrm{C}\right)$. Samples labelled with different lowercase letters are significantly different (Tukey's test, $p \leq 0.05$ )

Heating the seed prior to oil extraction can also affect the sensory characteristics of the produced virgin rapeseed oil, changing the characteristics from seed-like and nutty to roasty (30). Oil samples produced in our research were sensory evaluated by a panel and the results are given in Fig. 3. Conditioning had no effect on the colour and clarity of the produced oil and all four samples were given maximal values for these two parameters. The influence of the conditioning temperature on sensory characteristics can be observed in the changes of flavour of the oil. The strongest flavour of cold-pressed oil was seed-like, scoring 4.8 out of 5 . Seed-like flavour was not affected

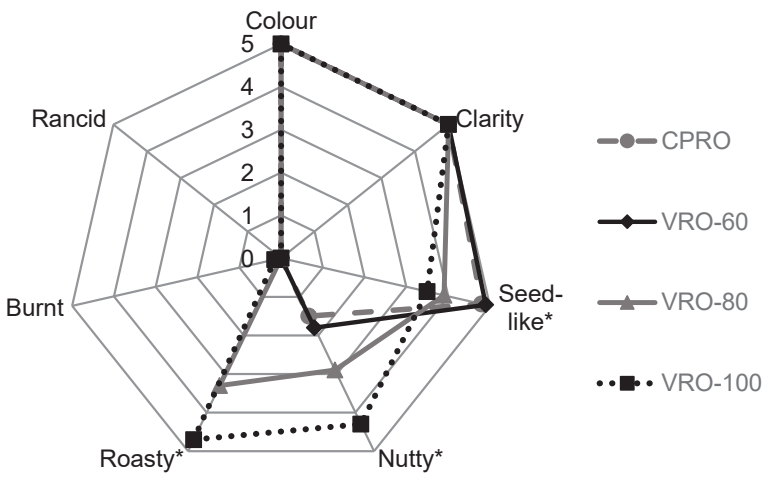

Fig. 3. Sensory characteristics of cold-pressed rapeseed oil (CPRO) and virgin rapeseed oil (VRO) produced after conditioning of the seeds at 60,80 and $100{ }^{\circ} \mathrm{C}$. ${ }^{*}$ Conditioning temperature had significant influence on the sensory attribute $(p \leq 0.05)$

by conditioning the seeds at $60^{\circ} \mathrm{C}$ for $30 \mathrm{~min}$. Additionally, both of these, cold-pressed and virgin oil preconditioned at $60{ }^{\circ} \mathrm{C}$, were characterized by medium intensity of nutty flavour and an absence of roasty and burnt flavour. Although seed-like and nutty flavour were slightly more enhanced in the latter, data analysis showed that there is no significant difference in the sensory characteristics between these two types of oil. On the other hand, flavours of the virgin oil samples preconditioned at 80 and $100^{\circ} \mathrm{C}$ were significantly different from those of coldpressed and the one preconditioned at $60^{\circ} \mathrm{C}$, and also from each other. Increasing conditioning temperature decreased the intensity of seed-like flavour in the virgin oil preconditioned at 80 and $100{ }^{\circ} \mathrm{C}$, simultaneously increasing nutty and roasty flavours of the produced oil. The decrease of seed-like flavour 
and increase of nutty and roasty flavour were consistent with the used temperature. Burnt flavour was detected, but in a very low intensity $(0.15)$, only in the virgin oil preconditioned at $100{ }^{\circ} \mathrm{C}$, and rancid flavour was not detected in any of the produced oil samples.

It is well known that the differences in the sensory characteristics of different types of oil, especially aroma is directly under the influence of volatile components present in the oil (31). Volatile components detected and identified in the obtained cold-pressed and virgin oil are shown in Table 3 $(10,14,21,22)$. A large number of compounds were detected and they were grouped in 11 categories (isothiocyanates, epithionitriles, nitriles, other sulfur and nitrogen components, pyrazines, aldehydes, ketones, alcohols, furan derivatives, and other components that cannot be placed in any of the aforementioned groups). Amount of every compound present in the oil is expressed by area of its peak, and for each compound, Kovats index is included (Table 3 ).

As we mentioned before, crucial point of the oil extraction is a rupture of the cell structure (3). Because of this, naturally present glucosinolates come in contact with enzymes, resulting in a variety of volatile products including isothiocyanates, thiocyanates, nitriles, epithionitriles etc. (32). Isothiocyanates are the most common products of glucosinolate hydrolysis catalysed by the myrosinase (33). The 4-isothiocyanato-1-butene was the major volatile component of our cold-pressed oil, making $56 \%$ of total volatiles. Wei et al. (14) also reported the same component as a dominant volatile compound

Table 3. Volatile components of cold-pressed rapeseed oil (CPRO) and virgin rapeseed oil (VRO) produced after conditioning of the seeds at 60 , 80 and $100^{\circ} \mathrm{C}$

\begin{tabular}{|c|c|c|c|c|c|}
\hline \multirow{3}{*}{ Component } & \multirow{3}{*}{ Kovats index } & \multicolumn{4}{|c|}{ Sample } \\
\hline & & CPRO & VRO-60 & VRO-80 & VRO-100 \\
\hline & & \multicolumn{4}{|c|}{ Peak area $\cdot 10^{7}$} \\
\hline & & & & & \\
\hline 1-isothiocyanatobutane ${ }^{*}$ & $929^{1}$ & $(8.3 \pm 0.1)^{b}$ & $(9.7 \pm 1.0)^{c}$ & $\mathrm{nd}^{\mathrm{a}}$ & $\mathrm{nd}^{\mathrm{a}}$ \\
\hline 4-isothiocyanato-1-butene & $982^{1}$ & $(2744.6 \pm 124.0)^{b}$ & $(4181.6 \pm 188.8)^{c}$ & $(553.3 \pm 49.5)^{a}$ & $(910.9 \pm 104.9)^{a}$ \\
\hline 4-methypentylisothiocyanate ${ }^{* \S}$ & 1161 & $(10.6 \pm 0.2)^{\mathrm{b}}$ & $(13.0 \pm 1.9)^{c}$ & $n d^{a}$ & $n d^{a}$ \\
\hline \multicolumn{6}{|l|}{ Eprithionitriles } \\
\hline 1-cyano-3,4-epithiobutane & $1118^{2}$ & $(132.3 \pm 1.5)^{d}$ & $(29.1 \pm 6.5)^{c}$ & $\mathrm{nd}^{\mathrm{a}}$ & $(15.9 \pm 7.0)^{\mathrm{b}}$ \\
\hline 1-cyano-4,5-epithiopentane ${ }^{*}$ & 1195 & $n d^{\mathrm{a}}$ & $n d^{\mathrm{a}}$ & $\mathrm{nd}^{\mathrm{a}}$ & $(22.3 \pm 9.3)^{b}$ \\
\hline \multicolumn{6}{|l|}{ Nitriles } \\
\hline 2-methyl-2-butenenitrile ${ }^{*}$ & $<800$ & $(172.9 \pm 3.5)^{\mathrm{a}}$ & $(193.1 \pm 4.5)^{\mathrm{a}}$ & $(234.3 \pm 27.1)^{a}$ & $(2680.6 \pm 145.5)^{b}$ \\
\hline 2,4-pentadienenitrile ${ }^{*}$ & $<800$ & $n d^{a}$ & $n d^{a}$ & $(5.7 \pm 0.7)^{\mathrm{a}}$ & $(190.6 \pm 9.7)^{\mathrm{b}}$ \\
\hline 5-methylhexanenitrile & 948 & $n d^{\mathrm{a}}$ & $n d^{\mathrm{a}}$ & $\mathrm{nd}^{\mathrm{a}}$ & $(17.8 \pm 2.1)^{b}$ \\
\hline heptanenitrile ${ }^{* \S}$ & 953 & $(63.7 \pm 0.7)^{\mathrm{a}}$ & $(59.6 \pm 5.0)^{\mathrm{a}}$ & $(58.5 \pm 9.4)^{\mathrm{a}}$ & $(178.2 \pm 2.2)^{b}$ \\
\hline benzenepropanenitrile ${ }^{* \S}$ & 1234 & $n d^{a}$ & $n d^{a}$ & $\mathrm{nd}^{\mathrm{a}}$ & $(25.0 \pm 5.3)^{\mathrm{b}}$ \\
\hline \multicolumn{6}{|l|}{ Sulfur components } \\
\hline carbonil sulfide $^{*}$ & $<800$ & $(39.4 \pm 2.0)^{b}$ & $(40.7 \pm 1.9)^{b}$ & $n d^{a}$ & $(62.6 \pm 5.2)^{c}$ \\
\hline ethanethiol ${ }^{*}$ & $<800$ & $(21.4 \pm 1.7)^{a}$ & $(15.1 \pm 3.0)^{\mathrm{a}}$ & $(14.1 \pm 5.2)^{\mathrm{a}}$ & $(283.3 \pm 15.0)^{b}$ \\
\hline dimethyl sulfide ${ }^{*}$ & $<800$ & $(62.4 \pm 2.9)^{\mathrm{b}}$ & $(26.9 \pm 8.4)^{\mathrm{a}}$ & $(34.4 \pm 4.2)^{\mathrm{a}}$ & $(54.7 \pm 9.4)^{\mathrm{b}}$ \\
\hline carbon disulfide $^{*}$ & $<800$ & $(114.5 \pm 9.5)^{c}$ & $(7.7 \pm 1.4)^{\mathrm{a}}$ & $(87.4 \pm 9.5)^{b}$ & $n d^{\mathrm{a}}$ \\
\hline dimethyl sulfone $e^{* \S}$ & 915 & nd & $5.3 \pm 1.2$ & $9.9 \pm 4.8$ & nd \\
\hline 4-ethyl-5-methyl thiazole ${ }^{* \S}$ & 1079 & $(450.7 \pm 9.0)^{c}$ & $(692.4 \pm 33.5)^{d}$ & $(132.2 \pm 22.0)^{\mathrm{a}}$ & $(270.5 \pm 17.1)^{b}$ \\
\hline \multicolumn{6}{|l|}{ Pyrazines } \\
\hline 2-methylpyrazine ${ }^{* \S}$ & 820 & $\mathrm{nd}^{\mathrm{a}}$ & $n d^{\mathrm{a}}$ & $\mathrm{nd}^{\mathrm{a}}$ & $(135.7 \pm 3.1)^{\mathrm{b}}$ \\
\hline 2,5-dimethylpyrazine ${ }^{* \S}$ & 911 & $\mathrm{nd}^{\mathrm{a}}$ & $n d^{a}$ & $n d^{a}$ & $(205.1 \pm 13.6)^{b}$ \\
\hline 2,6-dimethylpyrazine ${ }^{* \S}$ & 916 & $n d^{a}$ & $n d^{a}$ & $n d^{\mathrm{a}}$ & $(78.3 \pm 3.7)^{\mathrm{b}}$ \\
\hline 2-ethyl-6-methylpyrazine ${ }^{* \S}$ & 996 & $\mathrm{nd}^{\mathrm{a}}$ & $n d^{a}$ & $n d^{a}$ & $(58.0 \pm 12.6)^{b}$ \\
\hline 2-ethyl-3-methylpyrazine ${ }^{* \S}$ & 998 & $n d^{a}$ & $n d^{\mathrm{a}}$ & $\mathrm{nd}^{\mathrm{a}}$ & $(51.2 \pm 4.5)^{\mathrm{b}}$ \\
\hline 2-ethyl-5-methylpyrazine ${ }^{*}$ & 999 & $\mathrm{nd}^{\mathrm{a}}$ & $\mathrm{nd}^{\mathrm{a}}$ & $\mathrm{nd}^{\mathrm{a}}$ & $(79.0 \pm 7.6)^{b}$ \\
\hline 3-ethyl-2,5-dimethylpyrazine ${ }^{* \#}$ & $1075^{1}$ & $n d^{a}$ & $\mathrm{nd}^{\mathrm{a}}$ & $\mathrm{nd}^{\mathrm{a}}$ & $(67.9 \pm 6.9)^{b}$ \\
\hline \multicolumn{6}{|l|}{ Other nitrogen components } \\
\hline urea $^{*}$ & $<800$ & $\mathrm{nd}^{\mathrm{a}}$ & $n d^{\mathrm{a}}$ & $\mathrm{nd}^{\mathrm{a}}$ & $(159.7 \pm 23.5)^{b}$ \\
\hline 2,5-dimethylpyrroline ${ }^{*}$ & $<800$ & nd & $6.9 \pm 1.4$ & nd & nd \\
\hline isopropyl-1-butanamine ${ }^{*}$ & 806 & $n d^{a}$ & $\mathrm{nd}^{\mathrm{a}}$ & $\mathrm{nd}^{\mathrm{a}}$ & $(26.6 \pm 1.8)^{b}$ \\
\hline 4-methyl-2-pyrrolidinone* & 880 & $(20.4 \pm 1.9)^{b}$ & $(34.5 \pm 7.7)^{c}$ & $\mathrm{nd}^{\mathrm{a}}$ & $n d^{a}$ \\
\hline 1-(1H-pyrrol-2-yl)ethanone ${ }^{* \S}$ & 1063 & $n d^{a}$ & $n d^{a}$ & $\mathrm{nd}^{\mathrm{a}}$ & $(10.5 \pm 1.1)^{b}$ \\
\hline
\end{tabular}


Table 3. Continued

\begin{tabular}{|c|c|c|c|c|c|}
\hline \multirow{3}{*}{ Component } & \multirow{4}{*}{ Kovats index } & \multicolumn{4}{|c|}{ Sample } \\
\hline & & CPRO & VRO-60 & VRO-80 & VRO-100 \\
\hline & & \multicolumn{4}{|c|}{ Peak area $\cdot 10^{7}$} \\
\hline \multicolumn{5}{|l|}{ Furan derivatives } & \\
\hline furfural $^{* \S}$ & 828 & $\mathrm{nd}^{\mathrm{a}}$ & $\mathrm{nd}^{\mathrm{a}}$ & $\mathrm{nd}^{\mathrm{a}}$ & $(719.2 \pm 23.5)^{b}$ \\
\hline 2-furanmethanol ${ }^{* \S}$ & 858 & $n d^{a}$ & $n d^{a}$ & $n d^{a}$ & $(96.5 \pm 4.5)^{b}$ \\
\hline dihydro-2(3H-)-furanone ${ }^{* \S}$ & 907 & $(6.8 \pm 1.9)^{\mathrm{a}}$ & $(13.6 \pm 1.6)^{\mathrm{a}}$ & $(12.9 \pm 4.1)^{\mathrm{a}}$ & $(78.7 \pm 7.1)^{\mathrm{b}}$ \\
\hline 5-methyl-2-furfural ${ }^{* \S}$ & 962 & $\mathrm{nd}^{\mathrm{a}}$ & $\mathrm{nd}^{\mathrm{a}}$ & $n d^{a}$ & $(177.6 \pm 11.5)^{b}$ \\
\hline 5-ethyldihydrofuran-2(3H)-one $\mathrm{e}^{* \S}$ & 1049 & $(5.6 \pm 0.7)^{\mathrm{ab}}$ & $(9.3 \pm 1.0)^{c}$ & $(5.5 \pm 3.7)^{\mathrm{bc}}$ & $n d^{a}$ \\
\hline \multicolumn{6}{|l|}{ Aldehydes } \\
\hline propanal $^{*}$ & $<800$ & $\mathrm{nd}^{\mathrm{a}}$ & $\mathrm{nd}^{\mathrm{a}}$ & $\mathrm{nd}^{\mathrm{a}}$ & $(42.6 \pm 2.9)^{b}$ \\
\hline 3-methylbutanal ${ }^{*}$ & $<800$ & $n d^{a}$ & $(1.5 \pm 0.1)^{\mathrm{a}}$ & $(15.5 \pm 4.2)^{\mathrm{b}}$ & $(39.1 \pm 4.1)^{c}$ \\
\hline 2-methylbutanal* & $<800$ & $n d^{a}$ & $\mathrm{nd}^{\mathrm{a}}$ & $(23.3 \pm 4.4)^{\mathrm{b}}$ & $(76.7 \pm 17.2)^{c}$ \\
\hline hexanal ${ }^{* \S}$ & 801 & $(350.5 \pm 14.6)^{b}$ & $(179.2 \pm 2.4)^{\mathrm{a}}$ & $(316.5 \pm 27.1)^{b}$ & $(248.2 \pm 9.5)^{\mathrm{a}}$ \\
\hline heptanal ${ }^{* \S}$ & 902 & $(57.3 \pm 6.0)^{\mathrm{abc}}$ & $(44.6 \pm 3.1)^{\mathrm{ab}}$ & $(69.9 \pm 5.4)^{\mathrm{abc}}$ & $(75.1 \pm 11.8)^{\mathrm{ac}}$ \\
\hline 2-heptenal ${ }^{* \varsigma}$ & 960 & $10.3 \pm 3.4$ & $8.4 \pm 0.4$ & $14.6 \pm 2.0$ & nd \\
\hline octanal $^{* \S}$ & 1003 & $(29.7 \pm 1.6)^{\mathrm{a}}$ & $(34.6 \pm 6.8)^{a}$ & $(40.6 \pm 5.2)^{\mathrm{a}}$ & $(57.4 \pm 4.9)^{\mathrm{b}}$ \\
\hline phenylacetaldehyde ${ }^{* \#}$ & $1042^{3}$ & $n d^{a}$ & $\mathrm{nd}^{\mathrm{a}}$ & $(10.6 \pm 2.1)^{a}$ & $(52.0 \pm 4.0)^{\mathrm{b}}$ \\
\hline 2-octenal ${ }^{* \S}$ & 1058 & nd & $1.6 \pm 0.6$ & $2.4 \pm 0.9$ & $10.4 \pm 1.3$ \\
\hline nonanal $^{* \S}$ & 1103 & $(21.7 \pm 0.9)^{\mathrm{a}}$ & $(33.1 \pm 5.4)^{\mathrm{a}}$ & $(50.2 \pm 6.0)^{b}$ & $(79.1 \pm 7.7)^{c}$ \\
\hline \multicolumn{6}{|l|}{ Ketones } \\
\hline 2,3-pentadione ${ }^{*}$ & $<800$ & $\mathrm{nd}^{\mathrm{a}}$ & $n d^{a}$ & $(34.0 \pm 5.0)^{\mathrm{a}}$ & $(99.7 \pm 12.5)^{b}$ \\
\hline 2-heptanone $e^{* \S}$ & 891 & $n d^{a}$ & $(1.4 \pm 0.4)^{\mathrm{a}}$ & $(4.2 \pm 1.8)^{\mathrm{a}}$ & $(21.0 \pm 4.4)^{\mathrm{b}}$ \\
\hline 6-methyl-5-hepten-2-one ${ }^{* \S}$ & 987 & $23.2 \pm 8.5$ & $38.1 \pm 2.6$ & $30.7 \pm 8.8$ & $36.7 \pm 2.8$ \\
\hline 3-octen-2-one ${ }^{* \S}$ & 1039 & $(9.2 \pm 1.2)^{\mathrm{abc}}$ & $(6.3 \pm 1.2)^{\mathrm{ab}}$ & $(8.5 \pm 2.7)^{\mathrm{abc}}$ & $(17.0 \pm 4.4)^{\mathrm{ac}}$ \\
\hline 1-phenylethanone ${ }^{* \S}$ & 1065 & $(8.0 \pm 0.2)^{\mathrm{b}}$ & $n d^{a}$ & $\mathrm{nd}^{\mathrm{a}}$ & $n d^{a}$ \\
\hline \multicolumn{6}{|l|}{ Alcohols } \\
\hline 2-methylbutanol ${ }^{*}$ & $<800$ & nd & $4.9 \pm 0.5$ & $2.9 \pm 1.7$ & nd \\
\hline n-pentanol ${ }^{*}$ & $<800$ & $(96.1 \pm 3.4)^{c}$ & $(73.8 \pm 8.9)^{\mathrm{b}}$ & $(70.8 \pm 9.7)^{\mathrm{b}}$ & $n d^{a}$ \\
\hline n-hexanol ${ }^{* \S}$ & 874 & $(157.9 \pm 6.5)^{b}$ & $(114.0 \pm 19.9)^{b}$ & $(135.3 \pm 37.1)^{\mathrm{b}}$ & $(16.1 \pm 2.2)^{\mathrm{a}}$ \\
\hline 3-hepten-1-ol ${ }^{*}$ & 880 & $n d^{a}$ & $n d^{a}$ & $n d^{a}$ & $(61.5 \pm 17.0)^{b}$ \\
\hline n-heptanol ${ }^{* \S}$ & 976 & $(9.6 \pm 1.6)^{\mathrm{b}}$ & $(17.7 \pm 2.0)^{c}$ & $(2.6 \pm 1.2)^{\mathrm{ab}}$ & $n d^{a}$ \\
\hline 2-methyl-6-hepten-1-ol ${ }^{* \S}$ & 997 & $(56.0 \pm 5.2)^{\mathrm{b}}$ & $(58.2 \pm 11.2)^{\mathrm{b}}$ & $(43.0 \pm 8.7)^{b}$ & $n d^{a}$ \\
\hline 2,5-dimethylcyclohexanol ${ }^{* 5}$ & 1094 & $(6.8 \pm 2.1)^{\mathrm{b}}$ & $\mathrm{nd}^{\mathrm{a}}$ & $\mathrm{nd}^{\mathrm{a}}$ & $n d^{a}$ \\
\hline \multicolumn{6}{|l|}{ Other components } \\
\hline 2,2,3,3-tetramethylbutane ${ }^{*}$ & $<800$ & $18.0 \pm 3.2$ & $5.4 \pm 4.7$ & $12.3 \pm 2.3$ & $6.2 \pm 1.6$ \\
\hline 2,2,4-trimethylpentane ${ }^{*}$ & $<800$ & $(72.8 \pm 3.9)^{b}$ & $(35.2 \pm 7.1)^{\mathrm{a}}$ & $(81.3 \pm 7.3)^{b}$ & $(28.3 \pm 4.8)^{a}$ \\
\hline limonene $^{* \S}$ & 1027 & $(11.0 \pm 2.5)^{\mathrm{a}}$ & $(11.3 \pm 1.5)^{\mathrm{ab}}$ & $(14.8 \pm 0.7)^{\mathrm{b}}$ & $(18.4 \pm 0.9)^{c}$ \\
\hline 2-methoxy-4-vinylphenol ${ }^{* \S}$ & 1305 & $\mathrm{nd}^{\mathrm{a}}$ & $n d^{a}$ & $n d^{a}$ & $(23.6 \pm 6.9)^{b}$ \\
\hline
\end{tabular}

nd=not detected

"The compound was identified by comparison of mass spectra with mass spectra from NIST 05 (21)

${ }^{5}$ The compound was identified by comparison of retention indices with the ones obtained from the NIST 05 mass spectra library (21)

\#The compound was identified by comparison of retention indices with the ones in the literature ('Wei et al. (14), ${ }^{2}$ Kato et al. (22), ${ }^{3}$ Siegmund and Murkovic (10)). Different lowercase letters in the same row indicate significant difference between samples (Tukey's test, $p \leq 0.05$ )

of cold-pressed rapeseed oil. Conditioning the seeds for 30 min at $60^{\circ} \mathrm{C}$ further increased its content in the oil and 4 -isothiocyanato-1-butene accounted for more than $68 \%$ of total volatiles in the oil preconditioned at $60^{\circ} \mathrm{C}$. This increase was a result of prolonged contact of enzymes and glucosinolates during conditioning. Bones and Slupphaug (34) reported the temperature optima for rapeseed myrosinase to be between 70 and $75^{\circ} \mathrm{C}$, and for its inactivation temperatures higher than that should be used (3). The effectiveness of higher temperatures on myrosinase inactivation was also shown in our research. Increasing the conditioning temperatures to 80 and $100^{\circ} \mathrm{C}$ decreased isothiocyanate content to 24 and $9 \%$, respectively. Data analysis showed that the oil preconditioned at 80 and $100^{\circ} \mathrm{C}$ can be characterized with lower content of isothiocyanates and there was no significant difference between these two types of oil, while the cold-pressed and the one preconditioned at $60{ }^{\circ} \mathrm{C}$ were significantly different from the other two, and from each other (Tukey's test, 
$\mathrm{p} \leq 0.05)$. Isothiocyanates are the components that have the biggest impact on the specific seed-like flavour of the rapeseed oil (14), and their high content in our cold-pressed and virgin oil preconditioned at $60^{\circ} \mathrm{C}$ correlated with high scores for seed-like attribute of these two oil samples.

Nitriles and epithionitriles are also volatile products of glucosinolate hydrolysis by myrosinase, but in their formation epithiospecifier protein (ESP) is involved. ESP uses unstable thiohydroxymate generated by myrosinase to produce nitriles and epithionitriles. Due to its lower thermal stability than of myrosinase (33), it is to be expected that the cold-pressed oil has the highest content of epithionitriles and nitriles. Results of our research showed that the content of 1-cyano-3,4-epithiobutane was the highest in the cold-pressed oil and it decreased with the increase of temperature used for seed conditioning, with the exception of the oil preconditioned at 100 ${ }^{\circ} \mathrm{C}$, where its content was higher than in that preconditioned at $80^{\circ} \mathrm{C}$. In addition, 1 -cyano-4,5-epithiopentane was also detected, but only in the oil preconditioned at $100^{\circ} \mathrm{C}$. Similar to this, concentration of nitriles, with 2-methyl-2-butenenitrile, 2-methyl-5-hexanenitrile and heptanenitrile as dominant nitriles in the produced oil, increases with conditioning temperature, which was not in accordance with lower thermal stability of ESP. However, according to the literature, nitrile formation can also occur due to thermal decomposition of the glucosinolates (33), and Wei et al. (14) also reported an increase of nitriles in virgin rapeseed oil after microwave and thermal pretreatment of the rapeseed.

Except for isothiocyanates, nitriles and epithionitriles, other sulfur- and nitrogen-containing components were detected in the produced rapeseed oil. The 4-ethyl-5-methyl thiazole shows similar behaviour to isothiocyanates and is probably a product of myrosinase hydrolysis of glucosinolates. Except for 4-ethyl-5-methyl thiazole, relatively high content of carbon sulfide, ethanethiol, dimethyl sulfide and carbon disulfide was found in cold-pressed oil; however, their content changed in a completely opposite way than of 4-ethyl-5-methyl thiazole, indicating that they are a result of chemical rather than enzymatic process (35). According to Siegmund and Murkovic (10) and Mottram (36), these compounds are probably Strecker degradation products derived from methionine. Heating the seeds at $60^{\circ} \mathrm{C}$ resulted in the evaporation of these products, which were already present in the seeds, and therefore in the cold-pressed oil. Increasing the conditioning temperature to $80^{\circ} \mathrm{C}$ further decreased the content of carbonil sulfide and ethenethiol, but increased the content of dimethyl sulfide and carbon disulfide. Conditioning the seeds at the highest temperature resulted in acceleration of Strecker degradation reactions, which increased the amount of degradation products, except for carbon disulfide, which was not detected in the oil preconditioned at 100 ${ }^{\circ} \mathrm{C}$. The differences in the compound behaviour can be attributed to the differences in their volatility and/or their stability at high temperatures, but in general, we can conclude that the increase in conditioning temperature leads to an increase in the amounts of Strecker degradation products.
Pyrazines, pyrroles, pyrrolines and pyrrolidines are the typical compounds formed in the Maillard reactions and are found among the volatiles of most heated foods (36). Formation of these components positively correlates with heating time and temperature (10-12). Eight pyrazines were detected during our research, but only in the headspace of the virgin oil preconditioned at $100{ }^{\circ} \mathrm{C}$ : 2-methylpyrazine, 2,5-dimethylpyrazine, 2-ethylpyrazine, 2,6-dimethylpyrazine, 2-ethyl-6-methylpyrazine, 2-ethyl-3-methylpyrazine, 2-ethyl-5-methylpyrazine, and 2-ethyl-2,5-dimethylpyrazine. Formation of pyrazines at temperatures higher than $100{ }^{\circ} \mathrm{C}$ was previously reported (10), and their presence is associated with sensory attributes such as roasty, nutty, woody or burnt (37). The presence of pyrazines in the oil preconditioned at $100{ }^{\circ} \mathrm{C}$ was the reason for higher scores for nutty and roasty attribute in sensory evaluation than for other produced oil samples, as well as the appearance of burnt flavour. Pyrroles also contribute to the typical roasty flavour of oil (11). As well as the pyrazines, 1-(1 H-pyrrol-2-yl)ethanone was found only in the oil peconditioned at $100^{\circ} \mathrm{C}$, while 2,5-dimethylpyrroline and 4-methyl-2-pyrrolidinone were detected only in the oil produced at lower temperatures. Except for heterocyclic nitrogen compounds, isopropyl-1-butanamine and urea were also detected in the headspace of the oil peconditioned at $100^{\circ} \mathrm{C}$. These two components are probably products of amino acid degradation, i.e. Strecker degradation.

Furans (furfurals and furanones) are the most abundant products of Millard reaction and they occur in volatiles of all heated food. They are formed by degradation of carbohydrates and generally they give caramel-like, sweet and fruity characteristic to food (36). Furan derivatives have previously been reported in vegetable oil and although they are present in some cold-pressed types of oil, similar to other Millard reaction products, concentration of furans significantly increases with increase of temperature used during oil production $(10-12,38)$. Furanones identified in the present research were detected in all produced oils while furfurals (furfural and 5-methy-2-furfural) and 2-furanmethanol were detected only in the oil preconditioned at $100{ }^{\circ} \mathrm{C}$ and for their formation higher temperatures were needed. In general, this oil sample significantly differed from other obtained oil samples in the amount of furan derivatives $(p \leq 0.05)$ and they were, together with other Millard reaction products, responsible for its pronounced nutty and roasty flavour.

Ten aldehydes were identified in the produced rapeseed oil samples. They can be grouped into two groups, depending on their formation pathway: Strecker degradation products (3-methylbutanal, 2-methylbutanal and phenlyacetadehlde) and compounds derived from lipid oxidation (propanal, hexanal, heptanal, 2-heptenal, octanal, 2-octenal and nonanal). The amount of the Strecker degradation products increased with the increase of conditioning temperature, which was expected and consistent with previous findings (10). Dominant aldehyde in all produced oil samples was hexanal. It gives a green flavour to the oil and it is derived from linoleic acid already in 
the seed (39). Abundancy of hexanal decreased with increase of the production temperature to $60^{\circ} \mathrm{C}$, probably due to evaporation of hexanal present in the seeds. Using conditioning temperature of $80^{\circ} \mathrm{C}$ significantly increased peak area of hexanal but further increments of temperature significantly decreased its abundance. The 2-heptenal, which is also a product of linoleic fatty acid oxidation (40), showed similar behaviour, and this was probably due to volatility of these two aldehydes. Abundance of other detected aldehydes (propanal, heptanal, octanal, octenal, 2-octenal and nonanal) significantly increased with the increase of conditioning temperature, and in general, the virgin oil preconditioned at $100^{\circ} \mathrm{C}$ can be characterized with higher amounts of aldehydes derived from lipid oxidation. Ketones detected in our research are also products of fatty acid oxidation, and their abundance in the oil was changing in a similar manner as aldehydes derived from lipid oxidation. Most of the detected aldehydes and ketones are responsible for oily and fatty odour of the oil, but some contribute to nutty (2-octenal, 2-heptanone and 3-octen-2-one), green (hexanal, octanal, 2-octenal and nonanal) and even rancid (hexanal and heptanal) flavour of the oil (41). Since rancid flavour was not detected in neither of the produced oil samples during sensory evaluation (Fig. 3), we can conclude that lipid oxidation during conditioning even at $100^{\circ} \mathrm{C}$ was not expressed in such manner to cause sensory defects of the oil.

In addition to aldehydes and ketones, alcohols represent another characteristic group of fatty acid secondary oxidation products. In this research we detected seven alcohols: 2-methylbutanol, $n$-pentanol, $n$-hexanol, 3-hepten-1-ol, $n$-heptenol, 2-methyl-6-hepten-1-ol and 2,5-dimethylcyclohexanol. As a rule, the content of alcohol decreased with with the increase of temperature used for conditioning the seeds, except for 3-hepten-1-ol. Loss of alcohols at higher temperatures can partially be explained by volatility of these compounds, and partially by their oxidation and formation of the corresponding aldehydes (10).

Additionally, four other components were detected in produced rapeseed oil that cannot be placed in any of the aforementioned and discussed groups: 2,2,3,3-tetramethylbutane, 2,2,4-trimethylpentane, limonene and 2-methoxy-4-vinylphenol. Alkanes showed similar behaviour to Strecker degradation products. Abundance of limonene, a monoterpene common to many vegetal samples, increased with higher temperatures, which is in accordance with previous reports of its formation in peanut oil during roasting of seeds (11), and 2-methoxy-4-vinyphenol was found only in the oil preconditioned at $100^{\circ} \mathrm{C}$. This is expected since this oil has significantly higher canolol content than other produced samples, and 2-methoxy-4-vinyphenol is the most likely derived from canolol because of their similar molecular structure.

\section{CONCLUSIONS}

Conditioning the rapeseed prior to oil extraction had a favourable effect on the oil yield and its nutritional value, and it also completely changed sensory and aroma profile of the produced rapeseed oil. From an economical point of view, optimal conditioning temperature was $80^{\circ} \mathrm{C}$ with a $14 \%$ oil yield increase compared to cold pressing. Temperatures up to $100{ }^{\circ} \mathrm{C}$ and water addition during conditioning did not lead to any hydrolytic or oxidative deterioration of the oil, but heating at $80^{\circ} \mathrm{C}$, and especially at $100{ }^{\circ} \mathrm{C}$, significantly increased the amount of bioactive compounds. Therefore, from the quality and nutritional point of view, higher temperatures had more favourable effect. However, the greatest impact of conditioning temperature was observed on the volatile components, and therefore on sensory profile of the produced virgin rapeseed oil. Cold-pressed and virgin rapeseed oil produced at 60 ${ }^{\circ} \mathrm{C}$ were characterized by volatiles that are products of enzymatic degradation of glucosinolates (isothiocyanates and epithionitriles) and had expressed seed-like flavour. Increasing the conditioning temperature to 80 and $100^{\circ} \mathrm{C}$ caused inactivation of the enzymes and decrease in the intensity of seedlike aroma, but at the same time temperature increase caused thermal degradation of seed components and expression of nutty and roasty flavour. Results of this research, especially the ones about changes in the aroma and sensory profile, can help in production of high-quality rapeseed oil with desirable and very specific sensory attributes and ensure a greater selection of products for the consumers.

\section{FUNDING}

The present study was supported by the University of Zagreb, Croatia (support no. BT055).

\section{REFERENCES}

1. FAOSTAT. Rome, Italy: Food and Agiculture Organization of the United Nations (FAO); 2017. Available from: http://www. fao.org/faostat/.

2. Foreign Agricultural Service. Washington, WA, USA: United States Department of Agriculture (USDA); 2017. Available from: http://www.fas.usda.gov/.

3. Przybylski R, MagT, Eskin NAM, McDonald BE. Canola oil. In: Shahidi F, editor. Bailey's industrial oil and fat products. Hoboken, NJ, USA: John Wiley \& Sons, Inc.; 2005. pp. 61-121. https://doi.org/10.1002/047167849X.bio004

4. Azadmard-Damirchi S, Habibi-Nodeh F, Hesari J, Nemati M, Achachlouei BF. Effect of pretreatment with microwaves on oxidative stability and nutraceuticals content of oil from rapeseed. Food Chem. 2010;121(4):1211-5. https://doi.org/10.1016/j.foodchem.2010.02.006

5. CODEX-STAN 210-1999. Codex standard for named vegetable oils. Rome, Italy: Food and Agriculture Organization of the United Nations (FAO) and World Health Organization (WHO); 1999.

6. Vaidya B, Choe E. Effects of seed roasting on tocopherols, carotenoids, and oxidation in mustard seed oil during heating. J Am Oil Chem Soc. 2011;88(1):83-90.

https://doi.org/10.1007/s11746-010-1656-0 
7. Kraljić K, Škevin D, Pospišil M, Obranović M, Neđeral S, Bosolt T. Quality of rapeseed oil produced by conditioning seeds at modest temperatures. J Am Oil Chem Soc. 2013;90(4):589-99. https://doi.org/10.1007/s11746-012-2195-7

8. Spielmeyer A, Wagner A, Jahreis G. Influence of thermal treatment of rapeseed on the canolol content. Food Chem. 2009;112(4):944-8.

https://doi.org/10.1016/j.foodchem.2008.07.011

9. Shrestha K, De Meulenaer B. Effect of seed roasting on canolol, tocopherol, and phospholipid contents, Maillard type reactions, and oxidative stability of mustard and rapeseed oils. J Agric Food Chem. 2014;62(2):5412-9.

https://doi.org/10.1021/jf500549t

10. Siegmund B, Murkovic M. Changes in chemical composition of pumpkin seeds during the roasting process for production of pumpkin seed oil (Part 2: Volatile compounds). Food Chem. 2004;84(3):367-74.

https://doi.org/10.1016/S0308-8146(03)00241-3

11. Liu X, Jin Q, Liu YF, Huang J, Wang X, Mao W, Wang S. Changes in volatile compounds of peanut oil during the roasting process for production of aromatic roasted peanut oil. J Food Sci. 2011;76(3):C404-12.

https://doi.org/10.1111/j.1750-3841.2011.02073.x

12. Park MH, Jeong MK, Yeo J, Son HJ, Lim CL, Hong EJ, et al. Application of solid phase-microextraction (SPME) and electronic nose techniques to differentiate volatiles of sesame oils prepared with diverse roasting conditions. J Food Sci. 2011;76(1):C80-8.

https://doi.org/10.1111/j.1750-3841.2010.01954.x

13. Brühl L, Matthäus B. Sensory assessment of virgin rapeseed oils. Eur J Lipid Sci Technol. 2008;110(7):608-10.

https://doi.org/10.1002/ejlt.200700293

14. Wei F, Yang M, Zhou Q, Zheng C, Peng JH, Liu CS, et al. Varietal and processing effects on the volatile profile of rapeseed oils. LWT - Food Sci Technol. 2012;48(2):323-9.

https://doi.org/10.1016/j.lwt.2012.04.007

15. ISO 659:2009. Oilseeds - Determination of oil content (Reference method). Geneva, Switzerland: International Organization for Standardization (ISO), 2009.

16. ISO 665:2000. Oilseeds - Determination of moisture and volatile matter content. Geneva, Switzerland: International Organization for Standardization (ISO), 2000.

17. ISO 660:2009. Animal and vegetable fats and oils - Determination of acid value and acidity. Geneva, Switzerland: International Organization for Standardization (ISO), 2009.

18. ISO 3960:2007. Animal and vegetable fats and oils - Determination of peroxide value - lodometric (visual) endpoint determination. Geneva, Switzerland: International Organization for Standardization (ISO), 2007.

19. ISO 5509:2000. Animal and vegetable fats and oils - preparation of methyl esters of fatty acids. Geneva, Switzerland: International Organization for Standardization (ISO), 2000.
20. ISO 9936:2006. Animal and vegetable fats and oils - Determination of tocopherol and tocotrienol contents by high-performance liquid chromatography. Geneva, Switzerland: International Organization for Standardization (ISO), 2006.

21. NIST Mass Spectral Library, NIST 05. Gaithersburg, MD, USA: National Institute of Standards and Technology; 2005. Available from http://www.nist.gov.

22. Kato M, Imayoshi $Y$, Iwabuchi $H$, Shimomura K. Kinetic changes in glucosinolate-derived volatiles by heat-treatment and myrosinase activity in Nakajimana (Brassica rapa L. cv. Nakajimana). J Agric Food Chem. 2011;59(20):11034-9. https://doi.org/10.1021/jf201626z

23. STATISTICA, v. 10. StatSoft, Inc, Tulsa, OK, USA; 2011. Available from: http://www.statsoft.com.

24. Wroniak M, Krygier K, Kaczmarczyk M. Comparison of the quality of cold pressed and virgin rapeseed oils with industrially obtained oils. Pol J Food Nutr Sci. 2008;58(1):85-9.

25. Fullana A, Carbonell-Barrachina AA, Sidhu S. Comparison of volatile aldehydes present in the cooking fumes of extra virgin olive, olive, and canola oils. J Agric Food Chem. 2004;52(16):5207-14. https://doi.org/10.1021/jf035241f

26. Qualified health claims. Silver Spring, MD, USA: US Food and Drug Administration; 2017. Available from: https://www. fda.gov/Food/LabelingNutrition/ucm2006877.htm.

27. Ferrari RAA, Schulte E, Esteves W, Brühl L, Mukherjee KD. Minor constituents of vegetable oils during industrial processing. J Am Oil Chem Soc. 1996;73(5):58792. https://doi.org/10.1007/bf02518112

28. Goffman FD, Möllers C. Changes in tocopherol and plastochromanol-8 contents in seeds and oil of oilseed rape (Brassica napus L.) during storage as influenced by temperature and air oxygen. J Agric Food Chem. 2000;48(5):1605-9. https://doi.org/10.1021/jf9912755

29. Szydłowska-Czerniak A, Karlovits G, Sosna-Sárdi Á, Dianoczki C, Szłyk E. Effect of hydrothermal treatment of rapeseed on antioxidant capacity of the pressed rapeseed oil. J Am Oil Chem Soc. 2009;86(8):817-25.

https://doi.org/10.1007/s11746-009-1407-2

30. Thiyam-Holländer U, Eskin NAM, Matthäus B, editors. Canola and rapeseed: Production, processing, food quality, and nutrition. Boca Raton, FL, USA: CRC Press; 2012.

31. Morales MT, Alonso MV, Rios JJ, Aparicio R. Virgin olive oil aroma - Relationship between volatile compounds and sensory attributes by chemometrics. J Agric Food Chem. 1995;43(11):2925-31. https://doi.org/10.1021/jf00059a029

32. Cole RA. Volatile components produced during ontogeny of some cultivated crucifers. J Sci Food Agric. 1980;31(6):549-57. https://doi.org/10.1002/jsfa.2740310606

33. Bones AM, Rossiter JT. The enzymic and chemically induced decomposition of glucosinolates. Phytochemistry. 2006;67(11):1053-67.

https://doi.org/10.1016/j.phytochem.2006.02.024 
34. Bones AM, Slupphaug G. Purification, characterization and partial amino acid sequencing of $\beta$-thioglucosidase from Brassica napus L. J Plant Physiol.1989;134(6):722-9.

https://doi.org/10.1016/s0176-1617(89)80034-3

35. Gracka A, Jeleń HH, Majcher M, Siger A, Kaczmarek A. Flavoromics approach in monitoring changes in volatile compounds of virgin rapeseed oil caused by seed roasting. J Chromatogr A. 2016;1428:292-304.

https://doi.org/10.1016/j.chroma.2015.10.088

36. Mottram DS. The Maillard reaction: Source of flavour in thermally processed foods. In: Berger RG, editor. Flavours and fragrances: Chemistry, bioprocessing and sustainability. Berlin, Germany: Springer; 2007. pp. 269-83. https://doi.org/10.1007/978-3-540-49339-6_12

37. Maga JA, Sizer CE. Pyrazines in foods. A Review. J Agric Food Chem. 1973;21(1):22-30. https://doi.org/10.1021/jf60185a006
38. Hu W, Zhang L, Li P, Wang X, Zhang Q, Xu B, et al. Characterization of volatile components in four vegetable oils by headspace two-dimensional comprehensive chromatography time-of-flight mass spectrometry. Talanta. 2014;129:629-35.

https://doi.org/10.1016/j.talanta.2014.06.010

39. Morales MT, Rios JJ, Aparicio R. Changes in the volatile composition of virgin olive oil during oxidation: Flavors and off-flavors. J Agric Food Chem. 1997;45(7):2666-73.

https://doi.org/10.1021/jf960585+

40. Jeleń HH, Mildner-Szkudlarz S, Jasińska I, Wąsowicz E. A headspace-SPME-MS method for monitoring rapeseed oil autoxidation. J Am Oil Chem Soc. 2007;84(6):509-17. https://doi.org/10.1007/s11746-007-1072-2

41. Petersen KD, Kleeberg KK, Jahreis G, Busch-Stockfisch M, Fritsche J. Comparison of analytical and sensory lipid oxidation parameters in conventional and high-oleic rapeseed oil. Eur J Lipid Sci Technol. 2012;114(10):1193-203. https://doi.org/10.1002/ejlt.201200112 